\title{
Template Free Synthesis and Enhanced Photocatalytic Activity of Anatase $\mathrm{TiO}_{2}$ Microsphere
}

\author{
Salma M. Z. Al Kindy, Mouza Al Ruqaishy, Faisal Al Marzouqi, Rengaraj Selvaraj \\ Department of Chemistry, College of Science, Sultan Qaboos University \\ P.C. 123, Al-Khoudh \\ Muscat, Sultanate of Oman \\ alkindy@squ.edu.om; u102373@student.squ.edu.om; faisalm123@hotmail.com; rengaraj@squ.edu.om
}

\section{Extended Abstract}

The discharge of synthetic and chemically active dyes in to industrial wastewater is a major environmental concern due to their carcinogenic nature. Further, the development of colour due to the presence of these dyes can block sunlight and decrease oxygen dissolution resulting in low photosynthetic activity for aquatic biota. It is, therefore, direly important to treat these coloured effluents before they enter into aquatic bodies. To combat this issue, a relatively new and promising set of techniques, called Advanced Oxidation Processes (AOPs) have been developed and employed for dye contaminated industrial effluents treatment [1-2]. Heterogeneous photocatalysis, a promising approach of AOPs, has successfully been developed and improved in recent years for better treatment of dyes in effluents. Nanostructures have drawn significant attention and incredible performance in photo driven chemical conversion area due to its unique physicochemical properties. Herein, we study the morphological influence of $\mathrm{TiO}_{2}$ microspheres on photocatalytic degradation of different organic dyes methylene blue, brilliant black and reactive red 120 presents in aqueous solution. $\mathrm{TiO}_{2}$ microspheres were synthesized by template free method by using various amount of titanium butoxide as precursor. The prepared $\mathrm{TiO}_{2}$ were characterized by X-ray diffraction (XRD), UV-vis diffuse reflectance absorption spectra (UV-DRS), X-ray photoelectron spectroscopy (XPS) and scanning electron microscopy (SEM). XRD analysis revealed that the template free synthesized $\mathrm{TiO}_{2}$ microsphere poses anatase phase with the presence of (101), (103). (004), (112), (200), (105), (211), (213), (116), (220) and (215). These peaks match exactly with the reported JCPDS No. 21-1272 corresponding to the anatase phase of $\mathrm{TiO}_{2}$. Based on the SEM analysis, the statistical analysis of synthesized $\mathrm{TiO}_{2}$ microspheres size ranging from 1 to $3 \mu \mathrm{m}$. The EDX and XPS analysis also confirmed that there are no elements other than Ti and $\mathrm{O}$ indicating the purity of the prepared samples. UV-DRS data shows that there is a blue shift in the band gap it may be attributed due to the growth $\mathrm{h}$ method and size. The photocatalytic degradation experiments were carried out with three different dyes such as methylene blue, brilliant black, reactive red-120 for four hours under UV light irradiation. The results show that $\mathrm{TiO}_{2} \mathrm{morphology}$ had great influence on photocatalytic degradation of organic dyes due to difference in specific surface area of nanostructures. The experimental results of dye mineralization indicated the concentration was reduced by a high portion of up to $99 \%$ within 4 hours. On the basis of various characterization of the photocatalysts, the reactions involved to explain the photocatalytic activity enhancement due to the concentration of titanium butoxide and morphology include a better separation of photogenerated charge carriers and improved oxygen reduction inducing a higher extent of degradation of aromatics [3].

\section{References}

[1] R. Selvaraj, K. Qi, S. M. Z. Al-Kindy, M. Sillanpää, Y. Kim, C-W.Tai, "A simple surfactant - free hydrothermal route for the preparation of $\mathrm{HgS}$ nanoparticles and their photocatalytic activities," RSC Advances., vol. 4, pp. 15371 $-15376,2014$.

[2] K. Qi, R. Selvaraj, T. Al Fahdi, S. Al-Kindy, Y. Kim, G-C. Wang, C-W Tai, M. Sillanpää, "Enhanced Photocatalytic Activity of Anatase- $\mathrm{TiO}_{2}$ Nanoparticles by Fullerene Modification: A Theoretical and Experimental Study," Applied Surface Science, vol. 387, pp. 750-758, 2016. 
[3] R. Selvaraj, T. Al Fahdi, B. Al-Wahaibi, S. M. Z Al-Kindy, K. Al-Nofli, H. Al-Lawati, "Nanotechnology: a clean and sustainable technology for the degradation of pharmaceuticals present in water and wastewater," Reviews on Environmental Health, vol. 31, pp. 75-78, 2016. 